\title{
A missão do homem do direito
}

\author{
Francisco Morato
}

Discurso pronunciado na cerimonia de colação de grau dos bachareis pela Faculdade de Dirento de São Paulo a 24 de Dezembro de 1924.

Meus senhores,

Não tendo tido até hoje a ventura de assistir, senão como espectador amigo, ás cerimonias das festas annuaes da collação de grau, é com timidez que vimos nellas collaborar, arrastado pela gentileza de discipulos, a quem com prazer e devotamento havemos dirigido e acompanhado pelo lapso afortunado de dous annos continuos.

Si foi na benevolencia que se assentou a nossa escolha para paranympho de 1924, ahi mesmo, por esperado e sempre requerido reflexo de sentimentos no auditorio, é que havemos de cobrar animo para as palaviras de acleus e sympathia com que nos despedimos dos que partem, a engrandecer e continuar, nos fastos da intellectualidade patria e nos bons successos da vida profissional, o renome, gloria e tradições da Faculdade de Direito de S. Paulo.

Para vós, meus queridos bacharelandos, que hoje vos fazeis nossos collegas e vos apparelhaes para os lances a que fôrdes chamados pelo destino ou pela inclinação, duplo é o sentido da solemnidade que celebramos: o do encerro 
da vida academica e o do introito da vida pratica. Por um lado, findam os dias porventura mais felizes e saudosos da existencia, com os quaes enchestes o tempo como no relampaguear de uma fuga, perfumados dos encantos da mocidade, ebrios dos rumores e alacridade da convivencia onde geram e estribam as affeições que nunca passam, envoltos de uma onda de innefavel doçura, num como ambiente de céo azul, invariavelmente sereno e prosperado; por outro, é a dispersão, o inicio da realidade, que atravez das alegrias e aborrimentos, vos haへde pôr em contacto, qualquer que seja a carreira, officio ou mistér que elegerdes, com todas as pequeninezas, precariedades e desillusões deste mundo quebradiço.

Mas, a realidade que vos aguarda, no proprio instante em que retinem os clarins da victoria academica, longe de vos quebrantar o animo ou entorpecer o enthusiasmo, deve vos lembrar a necessidade de vos engalanardes para o combate, saturando-vos ao mesmo tempo de coragem, de esperança e de fé, porque só na lucta é posisvel o triumpho e só triumphando logra o homem alçar-se um pouco acima dos que giram e tornejam pela craveira da vulgaridade. Si o caminho para a gloria do infinito é o dos padecimentos e revezes, a trilha para as palmas do mundanismo é a das contrariedades e obstaculos.

O ponto de vista dos que se revelam dignos do papel que lhes toca na ordem da creação, é o de comprehender e praticar aquillo que muitos não alcançam, fingem não enxergar ou desidenham de cumprir, a saber, que a nobreza da existencia não consiste em viver á imagem e semelhança de outros seres da escala zoologica, qual servo algemado da baixa animalidade, tranquillo e enfartado, em ocio imperturbavel, desfructando trabalhos e penas alheias, senão em viver em continua peleja, fluctuando entre os ardores de refregas incessantes e as alegrias que são a bençarn das fadigas afortunadas. O ponto de vista dos que conhecem e guardam a linha fronteiriça que aparta o rei das creaturas de outros componentes do reino animal, é o de enve- 
redar por esta trilha e nella persistir, conscios de que a lucta é pendão de dignidade, renovavel em todos os estadios e instantes, emquanto a morte não põe termo ao drama que se repete para cada qual com absoluta e inexoravel regularidade. O fim de um trabalho é o começo de um trabalho seguinte; quando o homem tiver acabado, estará então no começo, diz-se e sentencia-se na sabedoria do Ecclesiastes.

$\mathrm{Na}$ renovação do trabalho e na resistencia ás inclinacões peccaminosas, assegurada e procrastinada indefinidamente pela erronia da metempsychose ou transmigração das almas, punha a philosophia pagã o alicerce donde a creatura se guindava ao destino final do aperfeiçoamento proprio e imitação da divindade. Na continuidade do trabalho e na dominação dos impetos da fragilidade, assenta o christianismo a escada por onde se sobe ás doçuras da bemaventurança.

Para o homem do direito, si a perspectiva das luctas se defronta augmentada na razão da natureza da disciplina em que se forma, tambem recrescem e se multiplicam proporcionalmente as glorias e fructos da resistencia.

A formação do jurista é e não póde deixar de ser cosmopolita, obrigado como está a enfrentar problemas os mais complexos e assumptos que só the é possivel dirimir com as regras e noções da propria disciplina a que pertencem. Já tivemos occasião de commentar alhures e repetir desta tribuna, pensamento de notavel encyclopedista, de que o officio do homem de direito, sobretudo quando exercitado na advocacia, constitue a mais nobre das profissões, a profissão liberal por excellencia. Forçado a alliar, a notaveis aptidões litterarias e serios dotes de espirito, conhecimento profundo das cousas da vida commum e capacidade para penetrar themas os mais intrincados de outras profissões, seu mistér é em substancia o de propugnar pelo reino da justiça, distinguindo o justo do injusto. Ora, o justo e o injusto misturam-se a tantas e tão variadas paixões, que se pode dizer formarem o fundo mesmo da sociedade. A jus- 
tiça é o eixo em torno do qual revoluteiam todos os interesses da humanidade, a medulla ou principio dessa harmonia maravilhosa que o genio de Lerbnitz denominou de prestabelecida pela bondade e intelligencia de Deus.

Conseguintemente, occupando-se de distinguir o justo do injusto, o jurista exerce profissão difficilima, de feitio omnimodo, absorvente de outras disciplinas, em que, para se pôr á altura da carreira, tem de apurar os conhecimentos do proprio officio e de expandil-os pelo campo dos officios alheios.

$\mathrm{O}$ vosso ingresso na vidia pratica, meus jovens bachareis, opera-se em occasião em que o mundo em geral se acha em circumstancias de trevas, coincide com um momento de anormalidades que vos dão azo para corresponderdes ás esperanças de que sois depositarios e para fazerdes vibrar, na obra civica do reerguimento da patria e da sociedade, a voz do direito, do direito como sciencia do justo e do moral, na accepção mais ampla e significativa do termo.

E' de crises e derrocadas o periodo que atravessamos, em contraste com o progresso vertiginoso das industrias e sciencias. Por toda parte o estiolamento dos preceitos de civismo, de decencia, de moralidade e de religião, repercutindo molestamente na politica, na familia e na sociedade; por toda parte o predominio do sensualismo, as jactancias da frivolidade, a supremacia das incompetencias, o imperio da cobiça, as reivindicações do egualitarismo, as audacias do sovietismo e a soberania da vida accommodaticia, tudo em revolta permanente contra as leis da ordem divina $e$ humana.

Não são factos ineditos nem novidades de nossos dias. A historia está cheia destes collapsos do bom senso e silencios da dignidade. Recuando as vistas para acontecimentos de outras épocas, havemos de reconhecer que os eclypses que ensombram a actualidade são, com differença apenas de tonalidade ou de accidentes, os mesmos que conspurcaram o mundo contemporaneo de Caligula, de Nero ou de Henrique IV E' o nihil sub sole novum da sabedoria biblica; a 
repetição, nas grandes linhas, do que foi, do que é e do que ha-de ser.

Mas, houve nos tempos idos, como ha nos tempos presentes e ha-de haver nos tempos vindouros, um nucleo de homens de boa vontade e compostura sadia, deliberados a collaborar na obra da predestinação divina e a não permittir que se quebre a continuidade da civilisação ou se desloque o mundo da atmosphera serena da justiça e da moral, desse remanso dos grandes idéaes, desses páramos onde lampejam os esplendores da fé e onde o creado sente e prazer supremo da approximação do Creador.

Nesta peleja pelas idéas sãs, nesta cruzada de resistencia, cabe a primazia aos cultores das sciencias juridicas. $\mathrm{Na}$ magistratura, na advocacia, nas funcções legislativas, na administração publica ou onde quer que seja chamado a operar, desempenha o jurisperito papel de notavel relevo, pelo motivo que os principios em que plasma sua formação são os mesmos que constituem a base e fundamento da harmonia social.

Nesta peleja e cruzada, o que lhe cumpre é não se apartar do phanal em que illuminou o espirito e eleger o officio segundo a propria vocação.

Eleger a profissão, coisa é que não se resolve a esmo, ao intento directo e principal de accumular meios de vida, senão de accordo com as inclinações de cada qual. E' dever de todos seguir a vocação natural, desenvolvendo os dotes e aptidões que lhes são relevantes. No exercicio das propensôes naturaes, cumpre o homem uma das leis da creação, ao mesmo tempo que colhe os redditos com que provê as necessidades da existencia. Os recursos ou proventos não são o objecto primordial nem a caracteristica da profissão, mas apenas meios para o descnvolvimento das aptidões pessoaes e consequencias da actividade de cada um.

Por exemplo, a advocacia não é commercio para fazer dinheiro. O officio de advogado é combater pelo direito e quebnantar a iniquidade; os honorarios são meios que permittem o exercicio e continuidade de tão nobre profissão. 
O magistrado não exerce a judicatura como meio de angariar recursos; o magistrado recebe emolumentos como condição de subsistencia na missão delicadissima de distribuir justiça. O legislador, ainda até nos paizes onde os costumes politicos the têm permittido fazer disso profissão, não desempenha o mandato por officio de embolsar subsidios; o legislador percebe subsidios, para que a carencia do dinheiro caduco não o afaste da pena e sacrificio de velar pela fazenda publica e pelo bem da collectividade.

Talvez seja algo subtil a distincção, mas nem porisso deixa de scr real e de largas consequencias. Posto deseguaes os precalços e vantagens dos officios, não raro aquelles implicando trabalhos insolitos, estas carreando remuneraçôes mesquinhas, uns e outros desproporcionando-se nas penas e commodidades, o que é certo é que a ninguem é licito escolher carreira a que é infensa a propensão natural.

$\mathrm{Si}$, porém, é mau, em bom entendimento, professar contra a vocação, peior ainda é exercer naquillo que não é do officio. $\mathrm{Na}$ administração dos interesses particulares, na gestão dos negocios publicos, em todas as manifestações de actividade, é sempre causa de damnos e insuccessos occuparse o homem de assumptos extranhos ao seu mistér. Já advertia Aristoreles que não deve o sapateiro tocar flauta ncm o flautista fazer sapatos.

Quando alguem opera naquillo que não é de sua alçada, necessariamente ha-de occasionar triplice damno, não fazendo o que lhe cumpre executar, executando o que lhe incumbe não fazer e agindo mal no pouco que executa.

Um dos motivos do mal estar e dos erros que affligem as nações é por seguro o andar tudo invertido e deslocado, chamados os homens para funções que lhes excedem o entendimento ou para as quaes não fazem nenhum preparo ou tirocinio. Não póde haver obra perfeita, ainda mesmo para o mal, senão quando o artifice labora na sua especialidade.

Dissertando da relevancia deste preceito, citou VIEIRA um caso assombroso, que não é tropo nem rhetorica do insigne 
orador, mas verdade referida em synthese em um dos passos da Biblia.

Querendo punir os crimes de certos reis de Israel, permittindo que enganados se castigassem a si mesmos, seguindo os caminhos da ruina cuidando que eram os caminhos da conservação, deliberou Deus, no antigo estylo de sua justiça e providencia, convocar um conselho, afim de que the dissesse qual o modo para que fossem enganados os regios criminosos e a quem se devia commetter a empreza de enganal-os. No conselho, entre as personagens de todas as gerarchias celestes, tomou assento o demonio.

Como reza o texto do Livro dos Reis e adorna o commentario do insuperavel estylista, proposta a questão, responderam os anjos uns de um modo e outros de outro -. unus verba hujusmodi et alius aliter -, porque até entre os anjos póde haver variedade de opiniões, sem menoscabo de sua sabedoria nem de sua santidade. No ultimo logar fallou o demonio; fallou breve, resumido, substancial e resoluto. Si o intento (ponderou) era que acabassem os reis pelo engano, o meio mais apropositado para isso era que lhes mentissem os conselheiros e pessoa mais cabal para fazer mentir a todos era elle Lucifer, que fallaria por suas linguas, transformado em espirito de mentira.

Pasmou á assembléa, não tanto que nella fosse admittido a dizer e votar o genio do mal, pois no conselho de Deus como no conselho dos homens intervêm os diabos, com a só differença que naquelle entrou um e neste costumam entrar muitos; pasmou a assembléa de que, mal houvesse acabado de discursar o demonio, já de prompto lhe acceitasse o Senhor o voto e conselho.

A razão do successo está primeiramente em que o voto vencedor trazia a dupla gentileza de proporcionar o meio com o fim e de proporcionar o instrumento com o meio. Está segundamente no acerto profissional, pois si a proposta e a materia do conselho -- engano e trahição - era da profissão do demonio e não era da profissão dos anjos, bem seguro que aquelle havia de votar melhor que todos estes 
reunidos. Tanto importa que vote cada um no que exercita e que aconselhe no que professa (Vierra: Sermões, V-8).

Nada ha, senhores, de mais util para os povos e de consolador para os individuos que occupar-se cada qual daquillo que é do proprio officio. Advém dahi beneficios e utilidade para todos e para cada um em particular. Para todos, porque se abrandará na somma dos padecimentos geraes o coefficiente pavoroso da inexperiencia, da protervia, da incompetencia e da frivolidade; para cada um em particular, porque, aperfeiçoando-se pelo tirocinio e pelo estudo, encontra o homem, no proprio aperfeiçoamento, razão de grande alegria e goso espiritual.

E' sabido que, nas profissões liberaes e nas conquistas da intelligencia, os vultos que campeiam acima das multidões, são os que mais saboreiam o proprio valor.

RENAN, a despeito de sua deploravel rebeldia anticatholica, foi um genio, um espirito profundamente fino, fascinante pela delicadeza do pensamento, pela graça do estylo e pela novidade das idéas. Perpetuamente alegre e contente de si mesmo, revelando quando velho o bom humor e jovialidade que nunca o deixaram quando moço, pela razão que elle proprio dava, que, tendo-se divertido pouco na mocidade, havia guardado para a velhice todo o frescor das illusões; Renan, na justa observação de Jules Lemaitre, foi quem primeiro e talvez mais agudamente gosou do renanismo.

Nos tempos em que a tribuna parlamentar do Imperio resplendia, frequentada por Joaquim Nabuco, Gomes DE Castro, José Bonifacio, Ruy Barbosa e outros, era Ferreira Vianna o primus inter pares dos grandes oradores. Artista consummado da oratoria, eximio na dicção, harmonioso na linguagem, exhuberante nas figuras, sagacissimo na ironia, brincando com a palavra, colorindo-a, torcendo-a e meneiando-a com extrema gentileza e galanteria, Ferreira Vranna, como escreve Affonso Celso, si encantou e divertiu os contemporaneos, na verdade foi elle mesmo quem mais se encantou e divertiu com os fulgores do proprio verbo. 
Até na perfeição plastica, o phenomeno se reproduz e actúa de modo identico. No dizer de Lemartre, a mulher verdadeiramente bella é quem mais gosa de seus primores physicos, continuamente comprazida na consciencia da propria formosura e na contemplação geral dos admiradores. Quem mais se enlevou com a belleza de Cleopatra foi seguramente a mesma Cleopatra.

Parti, meus joven collegas, parti, defensores fieis e observantes dos mandamentos da sciencia em que vos diplomastes, resolutos a vos engolphar pelos clarões do direito com a mesma ousadia e seguridade com que as aguias não repudiadas no berço encaram de fito em fito a luz brilhantissima do sol. Sêde os apaixonados perpetuos da justiça, como os crentes que, na bella imagem de Camille Julian, nas horas de pugna ou nos instantes de julgamento solemne, na dôr ou no jubilo, no repouso ou no trabalho, têm o animo continuamente voltado para o symbolo do Nazareno, que a infancia enamorada divisa na suavidade do presepio, respirando flôres e misturando a alma á alma de todos os seres da creação, sempre perto de S. Francisco de Sales e sempre longe de Torquemada.

Ide, crentes de que na guarda e defesa dos principios da justiça; no esmero, probidade, independencia e exacção do dever; na constancia, devotamento e infatigabilidade do estudo; no gosto e pratica dos prazeres que são o rocio dos homens de espirito; em summa, na obra do proprio aperfeiçoamento, haveis de conquistar o mais bello de vossos triumphos e o mais consolador de vossos premios. Sêde contentes de vós mesmos, tomando na propria consciencia a medida de vossos meritos e acautelando-vos de aferil-os pela louvaminha desses entes que exaltam e applaudem com a bocca, gemendo e chorando com o coração; dessas figuras que, retratadas no espelho, vertem lagrimas sem dôr e disparam risos sem alegria; desses parasitas que um grande psychologo mais vivamente comparou ás quatro alimarias do Apocalypse, as quaes, tendo cada uma quatro rostos e 
quatro linguas, outra coisa não sabem dizer e não dizem senão amen.

Conta Castulho Antonio, no prologo dos Fastos de Ovidio, que viajando pelos mares das Antilhas algumas vezes se descortina pela atmosphera a mais esplendida miragem com que nunca olhos humanos se enlevaram; a realidade das terras, das montanhas, dos bosques, das cidades, das praias, das ondas, tudo apparece pelo natural debuxado e vivo no firmamento. São fallazes o desenho e as cores, mas retratam o que existe, o que é solido, o que se palpa, o que se demanda, o que emfim se possue; naquelle mappa aereo e fugitivo se espelha e se reconhece o que ainda se não descobre, mas já se presente, se advinha e se assevera.

Nas festas com que celebramos hoje a vossa formatura, si não vemos com os olhos, presentimos com as nossas preces e asseveramos com os nossos coracões os louros que vos hão-de coroar na vida pratica, enchendo simultaneamente de ufania a mãe querida espiritual que é a Faculdade de Direito de São Paulo. 